\title{
Dennis Martinez and the Uses of Theory
}

\author{
Stanley Fish $\nmid$
}

I.

On June 24, 1985, Dennis Martinez, then a pitcher for the Baltimore Orioles, was caught by journalist Ira Berkow in the act of talking to his manager, Earl Weaver, shortly before the beginning of a game with the Yankees. Berkow, sensing a story, approached Martinez and asked him "what words of wisdom had been imparted by the astute Weaver." Now Martinez is a pitcher who is unlikely ever to make it into the Baseball Hall of Fame, if only because he seems to experience every pitch as a discrete event, unrelated to either its predecessor or its successor; but if his baseball skills are suspect, his philosophical skills would seem to be beyond dispute. In response to Berkow's question, Martinez offered a twostage narrative. In the first stage he reports the event. "He [Weaver] said, 'Throw strikes and keep 'em off the bases,' . . . and I said, 'O.K.'" This is already brilliant enough, both as an account of what transpires between fully situated members of a community and as a wonderfully dead-pan rebuke to the outsider who assumes the posture of an analyst. But Martinez is not content to leave the rebuke implicit, and in the second stage he drives the lesson home with a precision Wittgenstein might envy: "What else could I say? What else could he say?" Or, in other words, "What did you expect?" Clearly, what Berkow expected was some set of directions or an articulated method or formula or rule or piece of instruction, which Martinez could first grasp (in almost the physical sense of holding it in his hand or in some appropriate corner of his mind) and then consult whenever a situation seemed to call for its application. What Berkow gets is the report of something quite different, not a formula or a method or a principle-in fact, no guidance at all-simply a reminder of something that Martinez must surely already know, that it is his job to throw a baseball in such a way as to prevent opposing players from hitting it with a stick.

Of course, there is more to it than that, but Weaver made no effort to "impart" that more, and indeed it would have been totally inappropriate for him to have done so. Were he either to explain the principles of pitching or to enumerate the possible situations that might arise during the

$\dagger$ Arts and Sciences Distinguished Professor of English and Law, Duke University.

1. Berkow, The Old and New Manager, N.Y. Times, June 26, 1985, at B13, col. 1. 
game and suggest strategies to deal with those situations, Martinez would be understandably incredulous and justifiably resentful. What Martinez is saying to Berkow is something like this: "Look, it may be your job to characterize the game of baseball in terms of overriding theories, but it's my job to play it; and playing it has nothing to do with following words of wisdom, whether they are Weaver's or Aristotle's, and everything to do with already being someone whose sense of himself and his possible actions is inseparable from the kind of knowledge that words of wisdom would presume to impart." In short, what Weaver says amounts to "Go out and do it," where "do it" means go and play the game. That is why both Weaver's counsel and Martinez' response must be without content. What they know is either inside of them or (at least on this day) beyond them; and if they know it, they did not come to know it by submitting to a formalization; neither can any formalization capture what they know in such a way as to make it available to those who haven't come to know it in the same way.

Let me extend the point by assuming that Martinez has walked the first batter (an all too possible occurrence) and the second baseman trots up to say to him, "There's a man on first base." What could he possibly mean? Gertainly he does not think that Martinez has already forgotten what he did only a few seconds ago. Rather he is prompting Martinez to remember what having a man on first base involves: the repositioning of both outfielders and infielders to deal with eventualities that have just become more likely, the narrowing of the options available to the batter who may now adjust his stance or choke up on the bat or steel himself to be more patient and discriminating than he might otherwise have been; the necessity of keeping in mind the next and then the next batter who, even though they have not appeared, are already factors in the situation. All of this and more is, in a sense, contained in "There's a man on first base," although those simple words will only convey that information to someone who literally carries it in his bones. ${ }^{2}$ One can imagine Berkow approaching the second baseman to ask him what counsel he gave to Martinez, and hearing in response, "I said, 'There's a man on first base,' and he said, 'O.K.' What else could he say? What else could I say?"

This doesn't mean that there's never anything else to say, in a formal or theoretical sense, about baseball; only that it is not always appropriate to say it, although there are times when it would not be appropriate to say anything else. Presumably, as the second baseman says what he says, an

2. In saying this I am arguing as I often do against the availability of a literal level of language. Meaning is always a function of the interpretive condition of production and reception and never a function of formal linguistic structures. The case against theory and the case against formalism are one and the same. See S. Fish, Is There A Text in This Class? 225-84 (1980). 
announcer up in the radio or television booth-more than likely a former player-is saying just the kind of things that someone like Berkow expects. That is, in the announcer's account of what has just happened, both the pitcher and the second baseman are in the act of consulting and applying a set of underlying rules or formal principles that underlie the skills of baseball in general and the skillful exercise of judgment in this situation in particular; and it is often the announcer's claim to know even more about these rules than the players themselves know. And, in fact, that is, I think, a justifiable claim, but it is a justifiable claim because knowledge of the rules is the game he is in (and, of course, it follows that he would be an expert in his own game), while the players are in quite another game which has, I would contend, only an oblique relationship to the announcer's account of it. My claim, in short, is that in this imagined scenario there are two distinct activities-playing baseball and explaining playing baseball-and that, in a strict sense (which I shall soon elaborate), there is no relationship between them whatsoever. ${ }^{3}$

The point may be clearer if we turn to another example, taken this time from the world of industrial research as reported by Donald Schön. ${ }^{4}$ It seems that a research and development team was experimenting with a paintbrush made of synthetic bristles. The bristles were superior in many ways to the old natural kind, but in one respect they were unsatisfactory: They did not deliver paint to a surface smoothly. The team tinkered with the bristles in an attempt to improve them, but to no avail, until someone suddenly said, "You know, a paintbrush is a kind of a pump." In fact no one (including the speaker) did know that until it was hazarded as an observation; but once hazarded it constituted a suggestion: "Let's think of a paintbrush as a pump and see where it get us." Where it got them was to a reconception of the entire problem which now appeared to be one not of individual bristles, but of the channels formed by bristles, channels

3. At this point, someone might raise what I call the "Charlie Lau Objection." Lau, now deceased, was a renowned batting coach who regularly turned .260 hitters into .300 hitters and whose "theories" were widely quoted and praised. How does one explain his success if not by reference to the theory with which he apparently taught so many? Of course, I was not myself privy to the Lau experience, but I am sure that part of that experience involved Lau regularly repeating pieces of his theory to his students. I would contend, however, that such repetition served less as instructions one was to follow than as reminders that something wasn't being done "just right." I would also contend that knowledge of that something was not produced by Lau's theory; nor could it be recovered by invoking the theory. Rather the theory operates as a verbal place-marker for a knowledge that develops in the context of a trial-and-error attempt to match an example (e.g., Ted Williams' swing). In other words, the articulation of the theory refers to knowledge acquired independently of it, and it serves as a mnemonic and exhortative device. Listening to theory talk may be a part of the experience of becoming a practitioner but not because theory talk would in any strong sense be generating the practice. See Fish, Fish v. Fiss, 36 STAN. L. Rev. 1325, 1329-30 (1984).

4. Schön, Generative Metaphor: A Perspective on Problem-Setting in Social Policy, in METAPHOR AND ThOught 254 (A. Ortony ed. 1979).

5. Id. at 257. 
whose properties were hydraulic and which could therefore be interrogated with the familiar vocabulary of mechanical engineering. ${ }^{b}$ In the end, the result was just the kind of paint flow the researchers were looking for and the new paintbrush was promptly dubbed a "pumpoid."

After rehearsing the story, Schön turns to the problem of describing what had happened and remarks that it would be tempting to conclude "that the researchers mapped their descriptions of 'pump' and 'pumping' onto their initial descriptions of 'paintbrush' and 'painting' "; but this would be incorrect, says Schön, because it would make a groping developmental process into a formal and explicit program. Rather than beginning with two lists of the formal properties of brushes and pumps and mapping one onto the other, the researchers began with what Schön calls "an unarticulated perception of similarity" which then provoked them to questions and experiments that elaborated and deepened the similarity to the point where it could be the object of an analytic description. "It is important to note," says Schön, "that the researchers were able to see painting as similar to pumping before they were able to say 'similar with respect to what." "10 That is, the formalization that one might think served as their guide in doing what they did was available to them only after they had done it. The similarity that now could be reduced to a list of matched components was the product and not the cause of the process of discovery. Only later and after the fact, Schön insists, did the researchers "develop an explicit account of the similarity, an account which later still became part of a general theory of 'pumpoids,' according to which they could regard paintbrushes and pumps, along with washcloths and mops, as instances of a single technological category."11 Moreover, he concludes, "to read the later model back onto the beginning of the process would be to engage in a kind of historical revisionism."12 It would be to confuse a retrospective account of what they had done-an account in which the characteristics and capabilities of pumps and paintbrushes are matched up so as to illustrate their membership in a single category-with an account of how they had done it. Insofar as there is now something in the world called the "theory of pumpoids" it would be a mistake to think of that theory as guiding the process by which pumpoids emerged as a solution to the problem the researchers originally faced. The solution-provoked by the intuitive, non-theoretical suggestion that we try thinking of paint-

\footnotetext{
6. Id. at 258 .

7. Id. at 260 .

8. Id. at 259 .

9. Id. at 260 .

10. Id.

11. Id.

12. Id.
} 


\section{The Uses of Theory}

brushes as pumps-came first and the theory followed in response to whatever pressures prompted them to present their achievement in terms more orderly and rule-governed than their actual experience of it.

One can imagine a situation in which the pressures flowed from the need for funds: They now have built a model of a pumpoid, but they need four and one-half million dollars to develop and manufacture it. What do they say in the application to the National Science Foundation or the Exxon Corporation? Well, one thing they wouldn't say-at least if they really wanted the money - would be, "Hey, one day Marty and Ellen and I were sitting around trying to make those bristles deliver paint, and out of the blue Ellen said, 'You know, you can think of a paintbrush as a kind of a pump." " Rather, they would eliminate from their presentation all traces of the fumbling, groping process by which they came to their triumph, and offer only their conclusions, now dressed up in the vocabulary of hydraulic flow and presented in terms as formal and mathematical as possible.

At this point, there would be those who would fault the researchers for falsifying their experience. They would be accused, in a word, of being dishonest, of suppressing what they knew to be the truth about the matter in order to secure monetary gain. But that would be much too harsh a judgment, and indeed it would be incorrect, for it would assume that the practice of applying for grants was or should be continuous with the practice of discovering or inventing. Think of the two practices as different answers to a single question: What do we have to do in order to reach our goal? When the goal is making the paint flow and flow smoothly, then what you have to do is eliminate the condition (the researchers called it "gloppiness") that now impedes flow, and your procedure is to look around for ways to do that. Presenting theories is not going to be one of those ways, any more than it would be a way of preventing the runner on first base from scoring. But when the goal is to get money from a foundation, then representing yourself as having followed or applied a theory is a very good way, and when you have recourse to it you are not being dishonest, you are being effective-just as you are being effective when you try out the suggestion that a paintbrush is similar to a pump in the absence of any theory of what the similarity is. I call this the "thesis of the plural honesties," and what it says is that in one case you are honestly attempting to get the brush to deliver paint and in the other you are honestly trying to get the foundation to deliver money.

You might reasonably be wondering what this all has to do with the discourse of law. Before I tell you, let me consolidate what I take to be the gains of my two examples: First, what they together suggest is that performing an activity-engaging in a practice-is one thing and discoursing 
on that practice another. Second, the practice of discoursing on practice does not stand in a relationship of superiority or governance to the practice that is its object. ${ }^{13}$ There are some baseball players who can talk about their craft in an analytic fashion, but that does not make them better baseball players than they would be if they couldn't; and there are some researchers who are good at thinking up ex post facto accounts of their accomplishment, but those accounts are not to be understood as recipes for that accomplishment. Even if the practitioners happen to be in possession of a theory of the activity in which they are engaged, the shape of that activity is not the result of the application of that theory. They do not use their account of what they are doing (assuming that they have one) in order to do it. They can, however, use their account of what they are doing to do something else, to perform as a play-by-play analyst or apply for a grant.

What is at stake here are two uses of the word "use": on the one hand, "use" in the sense of "making use of" as a component of a practice; on the other, "use" in the sense of using in order to generate a practice. It is in the first sense that baseball analysts and grant applicants use theory, and it is in the second sense that no one (this, at least, is my thesis) uses theory. That is, no one follows or consults his formal model of the skill he is exercising in order properly to exercise it. This should not be understood as a distinction between activities that are theoretical and activities that are not. No activity is theoretical in the strong sense of unfolding according to the dictates of a theory, and this includes the activities (for example) of analyzing baseball or applying for grants; for while they are to be distinguished from playing baseball and inventing pumpoids precisely by the self-conscious recourse to a theoretical mode of talk, that talk no more generates the shape of their own enactment than it generates the shape of what the talk is about (playing baseball and inventing pumpoids). As activities, analyzing baseball and applying for grants are just like playing baseball and inventing pumpoids in that those who are engaged in them make use of whatever comes to hand in the effort to achieve a practice-specific goal. Even if the skill one exercises in a practice is the skill of talking theory, this does not make the practice theoretical; it just means that in the judgment of the practitioner who wants to get something done, talking theory is one of the resources he employs in the course of doing it. Again, this does not mean that the skill depends on (in the

13. This argument, in its broader contours and with slight variations, is traced in Fish, Consequences, 11 CRITICAL TheORY 433 (1985); Knapp \& Michaels, A Reply to Richard Rorty: What Is Pragmatism?, 11 CRITICAL INQUIRY 466 (1985); Knapp \& Michaels, Against Theory, 8 Critical InQUIRY 732 (1982); Michaels, Response to Perry and Simon, 58 S. CaL. L. Rev. 673 (1985). Some of these essays are compiled in Against Theory (W.J.T. Mitchell ed. 1985). 
sense of flowing from) theory talk; it means simply that one expression of the skill is knowing when theory-talk will or will not be useful. While it is certainly the case that the successful performance of a skill will sometimes require the invocation of theory-even of a theory of that particular skill-it is never the case that the theory thus invoked is acting as a blueprint or set of directions according to which the performance is unfolding.

I should acknowledge here that what I intend by "theory" may seem to some to be excessively narrow. ${ }^{14} \mathrm{I}$ reserve that word for an abstract or algorithmic formulation that guides or governs practice from a position outside any particular conception of practice. A theory, in short, is something a practitioner consults when he wishes to perform correctly, with the term "correctly" here understood as meaning independently of his preconceptions, biases, or personal preferences. To be sure, the word "theory" is often used in other, looser ways, to designate high order generalizations, ${ }^{15}$ or strong declarations of basic beliefs, or programmatic statements of political or economic agendas, or descriptions of underlying assumptions. Here my argument is that to include such activities under the rubric of theory is finally to make everything theory, and if one does that there is nothing of a general kind to be said about theory. When I assert the lack of a relationship between theory and practice I refer to the kind of relationship (of precedence and priority) implied by the strongest notion of theory; the relationships that $d o$ exist between theory and practice (and there are many) are no different from the relationships between any form of talk and the practice of which it is a component.

\section{II.}

This brings us at last to the law and to the practice that is the almost exclusive focus of contemporary legal debate, judging. Now judging is both a practice much theorized about and a practice that is itself filled with theory or theory talk. As you may have suspected, what I want to say is that judging or doing judging is one thing and giving accounts or theories of judging is another, and that as practices they are independent, even though the successful performance of the first will often involve engaging in the second. That is, as a practice judging is one of those that includes as a part of its repertoire self-conscious reflection on itself, and therefore it seems counterintuitive to say that such self-reflection-such theorizing-is not to some extent at least constitutive of what it is reflecting on; but that is just what I will be asserting, and asserting in direct

14. This argument is further developed in Fish, supra note 13, at 442-43.

15. See id. at 442 (distinguishing "empirical generalizations" from "theory"). 
opposition to what is assumed by almost everyone in the legal academy, irrespective of doctrinal or political affiliation. What everyone assumes is that much in judging depends on what theory of judging a judge holds, and whether or not he holds it self-consciously. Here are some representative statements:

(1) First, a judge must have a theory of law proper . . . some rule of recognition that explains how to derive a text ("the law"). Second, the judge must have some theory about facts that determines which of the indefinitely large numbers of descriptions of "what happened" should be used in deciding the case. Third, a judge needs [a] theory of interpretation ..... And fourth, a judge needs a theory about logic and its place in legal reasoning. ${ }^{16}$

(2) [W]e hope to develop a positive theoretical account of the grounds of law, a program of adjudication we can recommend to judges and use to criticize what they do. ${ }^{17}$

(3) [E]very branch of doctrine must rely tacitly if not explicitly upon some picture of the forms of human association that are right and realistic in the areas of social life with which it deals. If, for example, you are a constitutional lawyer, you need a theory of the democratic republic that would describe the proper relation between state and society or the essential features of social organization and individual entitlement .... Without such a guiding vision, legal reasoning seems condemned to a game of easy analogies. ${ }^{18}$

These three statements are essentially in agreement with one another in several important respects: They hold first that judges and lawyers need a theory in order properly to perform their tasks; second, that a theory selfconsciously wielded would provide both a program for judging and a model in relation to which individual acts of judging can themselves be judged; and third, that, in the absence of such a program or model, judging and lawyering are random, ad hoc activities, at the mercy of whatever presentation of the facts seems at the moment to be the most persuasive. As our third theorist puts it in his very next sentence, in the absence of a theory, "[i]t will always be possible to find, retrospectively, more or less convincing ways to make a set of distinctions, or failures to distinguish, look credible." ${ }^{19}$ Remarkably, our three authors occupy very distinct and opposing positions in the world of legal theory. The author of the first statement is Michael Moore, who bills himself as a natural law theorist,

16. Moore, A Natural Law Theory of Interpretation, 58 S. CAL. L. REv. 277, 283 (1985).

17. R. DWORKIN, LAw's EMPIRE 79 (1986).

18. Unger, The Critical Legal Studies Movement, 96 HArv. L. Rev. 561, 570 (1983).

19. Id. 
as someone who believes that we should comport ourselves in relation to general and abiding truths, irrespective of what is urged on us by presently enacted law or conventional systems of opinion. The second statement is taken from the recent work of Ronald Dworkin, who urges judges to look to the history of the judicial enterprise-a history Moore would finally have us set aside-for a "coherent theory"20 that would guide particular decisions. And the final statement comes to us from Roberto Unger, the prophet, if not the messiah, of the Critical Legal Studies Movement, who sees in judicial history a dismal record of mystification and oppression that will only be removed when a world of contending interests is replaced by a world in which men and women of enlarged sympathies exist in a relationship of reciprocal support that renders the machinery of legal culture obsolete. In short, the right, center, and left $\mathrm{t}^{21}$ of the legal academy are at odds with one another on every other point except on the point that what is required if our situation is to be improved (and perhaps even perfected) is the right theory. ${ }^{22}$

In what follows I will contend (1) that in whatever form it appears the argument for theory fails, (2) that theory is not and could not be used to do what Moore, Dworkin, and the Critical Legal Studies movement want it to do, generate and/or guide practice, (3) that when theory is in fact "used" it is in the way Unger so dislikes, in order "retrospectively" to justify a decision reached on other grounds, (4) that theory is essentially a rhetorical and political phenomenon whose effects are purely contingent, and (5) that these truths are the occasion neither of cynicism nor of despair.

I will begin with Moore, whose essay, A Natural Law Theory of Interpretation, ${ }^{23}$ illustrates an assumption that is crucial to the argument for theory, the assumption that the practice of judging will vary according to the theory the judge uses. ${ }^{24}$ The question Moore asks is whether judges should use a conventionalist or realist theory in order to do their jobs. A conventionalist theory is one that in response to the question, "Where do values, meanings, and facts come from?" answers, "From culture and his-

20. R. Dworkin, supra note 17 , at 245.

21. I use right, center, and left to denote places in the intellectual rather than political landscape. It may be the case that in some instances a person's place on the intellectual and political continuum will overlap.

22. For other accounts of judging premised on the belief that theory has consequences, see $P$. Brest \& S. Levinson, Processes of Constitutional. Decisionmaking (2d ed. 1983); R. WasSERSTrom, The Judicial Decision (1961). These questions continue to be debated. See, e.g., Colloquy: Does Constitutional Theory Matter?, 65 TEx. L. REv. 766 (1987).

23. Moore, supra note 16.

24. For another application of this analysis, see Fish, supra note 13, at 445-47 (discussing Thomas Grey's argument that theories of constitutional interpretation have consequences for judicial process). 
tory," that is, from man-made or conventional structures. In response to the same question a realist theory would answer, "Facts, meanings, and values come from God and nature, or from the divine Nous or the eternal structure of rationality." It is Moore's thesis that it is always better-in the sense that you will get better results-to use a realist theory in the course of reaching a decision. For example, when a judge must determine the meaning of a statute or a phrase from the Constitution, he should be guided "by the real nature of the things to which the words refer and not by the conventions governing the ordinary usage of those words." ${ }^{25}$ The reasoning is that "ordinary usage" is a reflection of what people happen to think about a matter rather than a reflection of what is really true. Thus, for example, (the example is Moore's) a case might well turn on the question of whether or not someone was in fact dead, and Moore's counsel is that if as judges we must rule on this question on our way to delivering an opinion, we should be guided

not by some set of conventions we have agreed upon as to when someone will be said to be dead; rather, we will seek to apply "dead" only to people who are really dead, which we determine by applying the best scientific theory we can muster about what death really is. ${ }^{26}$

Now, as you may have noticed, this is a sentence that cannibalizes itself. The first part of the sentence is unexceptionable. It says: When you are called upon to stipulate as to a matter of fact, go with what you take to be the truth and not with a specification or definition that has been handed down by some political or institutional body. However, it is to just such a body that the second part of the sentence counsels us to go in search of what is really-i.e., non-conventionally-true: We must, Moore says, apply "the best scientific theory we can muster about what death really is." Moore really isn't urging us to be realists at all; he's urging us to be one kind of conventionalist rather than another, and telling us that if we have been offered two conceptions of what death is, one by the legislature of California and the other by the most recent issue of the New England Journal of Medicine, we should go with the New England Journal of Medicine. Moreover, although Moore doesn't say so, the basis of his advice is a faith in the division of labor implicit in our present institutional structures: Judges determine what the law is; scientists and research physicians determine what it is to be "really" dead. It is an arguable point, but on whatever side of the argument you happen to be, you will not be upholding the banner of epistemological realism. No matter how

25. Moore, supra note 16 , at 287.

26. Id. at 294 . 
intriguing the choice between conventionalist and realist theories may be on a meta-critical level, it has no role whatsoever to play on the level of practical action, since wherever you turn in the world the sources of your knowledge and convictions will be conventional.

In a way Moore knows this, since he acknowledges (on the very same page) that the "best scientific theories we have" may be inadequate since they only reflect our present state of knowledge; but he says a realist will have the advantage of knowing, as his conventionalist opposite will not, that there is in fact something beyond our present state of knowledge, something toward which we are striving. "A realist ... believes that there is more to what death is (and thus what 'death' means) than is captured by our current conventions." Yes, but that knowledge (or, more properly, belief) doesn't do him any good, doesn't place him in any better position than the conventionalist when it comes to making actual decisions and determinations. He must still rely on whatever body of conventional knowledge he takes to be authoritative for whatever reasons.

Does this mean that the self-proclaimed realist theorist is in fact a conventionalist theorist without knowing it? Not at all. What it means is that he is not a theorist of any kind, at least when he is in the process of deciding whether or not someone is dead. At that moment he is listening to arguments with an ear already informed by a sense of what is and is not evidence, and of what, in the field of evidence, is weighty and conclusive. To be sure, any sense of the evidentiary will have its source in-be a function of-some- conventional system of assumptions in which authority is located in particular institutions or procedures, but the decisionmaker is not using that system (or any other); rather it is what he sees with, or more precisely, it is within it that he sees, and he will see what he sees independently of whether his theory of knowledge (should he have one) is realist or conventionalist. ${ }^{27}$ That is, the realist theorist will know, by virtue of his theory, that there is something beyond or behind the conventions that are currently established, but that knowledge will not help him either to set those conventions aside or to determine which of them is a better approximation of what the facts "really" (independently of convention) are. On the other side (which in my argument will turn out to be the same side), the conventionalist theorist will be similarly disappointed by his theory should he turn to it in a moment of epistemological need. What the conventionalist theorist's theory tells him is that knowledge and certainty have their source in culture and history rather than in nature and God. What the conventionalist theorist's theory won't tell him is where precisely in culture and history to look for the resolution of a current

27. See Fish, supra note 13 , at $443-44$. 
dilemma. That is, his theory won't give him a method for deciding whether or not someone is dead; all it will do is assure him that whatever he decides, the basis of decision-the facts that seem indisputable to him, the procedures that he regards as obligatory, the inferences that simply cannot be avoided-will be conventional through and through. Nor will this conviction of conventionality and its pervasiveness lead him to distrust either the conclusion he reaches or the means he employs to reach it. Such distrust could only follow if being a conventionalist theorist meant that you had a heightened (and confidence eroding) sense that everything you saw was "merely" conventional, that is, unreal; but the conventionalist theorist, no less than his realist counterpart, is wholly informed by whatever conventions now structure his consciousness and perception, and his conviction that conventions cover the field and are the source of everything he knows will not shake or even be seen to have a bearing on whatever convictions and pieces of knowledge those conventions have now delivered. He may be a conventionalist when you ask him whether knowledge derives from nature or from culture, but when he knows something it will be with all the confidence any realist could ever desire. In the case of either theorist the answer to the question, "How is it that we know what we know?" cannot be translated into a recipe for knowing; you don't use your account of knowing in order to "do" knowing.

Curiously enough, this is the same conclusion Moore reaches, although with a different emphasis. There may be those who espouse a subjectivist or conventionalist epistemology, "but when it comes to daily living they make judgments and decisions as we all do: presupposing the existence of tables, chairs, and right answers to hard moral dilemmas and legal cases. They are skeptics in their explicitly philosophical moments, and realists when it counts in daily living."28 Moore takes this as evidence that such theorists, no matter what they say, are using a realist, not a conventional-

28. Moore, supra note 16, at 310. Moore's distinction between skeptical beliefs and those of "daily living" is familiar to modern and contemporary philosophy. See D. HumE, A TREATISE of Human Nature 267-69 (L. Selby-Bigge rev. ed. 1975); Clark, The Legacy of Skepticism, $69 \mathrm{~J}$. PHIL. 754 (1972) (distinguishing "plain" from "philosophical" ways of interpreting statements).

Moore makes this point in the context of a familiar anti-anti-foundationalist argument. A conventionalist, he says, cannot coherently and seriously assert the truth of his conventionalist views for to do so would be to assume the very foundationalist stance he is denying. He therefore faces a dilemma: either he asserts his anti-foundationalism strongly and thereby contradicts it (by claiming that something-anti-foundationalism-is foundationally the case) or he clings to his anti-foundationalism and thereby forfeits his claim on our attention (we cannot take anything he says seriously). Moore, supra note 16, at 310-11. The dilemma does not exist. The thesis of anti-foundationalism is not that there are no foundations, but that whatever is taken to be foundational has to be established in the course of argument and debate and does not exist to the side of argument and debate. This thesis includes itself within its own scope, not in any self-contradictory sense, but in the sense that it too must make its way in the face of counterexamples and purportedly "irrefutable" evidence. To put it another way, the assertion that everything is in principle challengeable does not in and of itself constitute a challenge to any assertion. See S. FisH, supra note 2 , at $368-70$. 
ist, epistemology. I take it as evidence that they are not using any epistemology (or theory) at all. They are merely registering what they see and proceeding in ways that seem to them to be obligatory and routine, and they do these things not because they have applied this or that epistemology, but because within the beliefs and assumptions that constitute their perception and their sense of possible courses of action, there is nothing else they could do. What this means is that, as Moore later says, we are all realists; but we are all realists only in the sense that we all believe what we believe, and that we take what we believe to be true. This, in fact, is what it means to believe something-to take it to be the case-and it requires no special effort of the will, no assumption of a particular epistemological style, to be guided by that which, according to our lights, is really true. (What else could we do? What else could anyone do?). But if it is in this sense that we are all realists, then by the same argument we are all conventionalists. If it is only "according to our lights" that the category of the "really true" acquires its members, then the "really true" is always and already a conventional category, and there is no possibility of identifying a "really true" that is independent of any convention whatsoever. The conclusion-and it is not a paradoxical one-is that we are both realists and conventionalists, realists in that we "naturally" proceed in accordance with what we take to be the truth of the matter, and conventionalists in that what we take to be the truth of the matter will always have its source in conventions.

To this conclusion we must add another and more important one: The condition of being both realist and conventionalist is not a condition we self-consciously choose. Realism and conventionalism are the names of philosophical positions on the question of how it is that we know what we know; they are not the names of epistemological programs that one could self-consciously put into action. One could not determine to "do" conventionalism or realism, and therefore the shape of what one does in fact do will have no causal relationship to the account one might give of doing it. Two judges might differ in their assessments of whether someone was really dead for all kinds of reasons, but one of those reasons would not be a difference in their epistemological theories.

\section{III.}

Another way to make my point would be to say that when judges do what they do, they do not do it in accordance with or at the behest of some systematic and coherent account of law and its relation to morality and society. Judging, in short, cannot be understood as an activity in the course of which practitioners regularly repair for guidance to an underlying set of rules and principles. But, one might object, that is exactly the 
description of judging that judges themselves offer. As Ronald Dworkin observes,

when good judges try to explain in some general way how they work .... [t]hey say, for example, . . . that they are enforcing an internal logic of the law through some method that belongs more to philosophy than to politics, or that they are the agents through which the law works itself pure . . . ${ }^{28}$

That is, they picture themselves as striving to achieve what Dworkin calls "articulate consistency,"30 a way of deciding cases that ties the most recent decision to "some comprehensive theory of general principles and policies that is consistent with other decisions also thought right."31 Dworkin's example is a congressman who "votes to prohibit abortion, on the ground that human life in any form is sacred, but then votes to permit the parents of babies born deformed to withhold medical treatment that will keep such babies alive." ${ }^{32}$ Such a person, Dworkin announces, cannot, by the "principle of responsibility," be allowed these two votes "unless he can incorporate the difference within some general political theory he sincerely holds." ${ }^{\text {s3 }}$ It is Dworkin's thesis that this act of "incorporation," this fashioning of "articulate consistency," is or should be the form of judicial decisionmaking. It is his claim that what judges do when they are really doing their job is work out the present decision in relation to a general theory whose demands must be met if the decision is to be a responsible one, and whose articulations guide, almost in the sense of generating, that decision. He acknowledges that this remains an ideal and that most judges unfortunately are not so self-consciously reflective about their practice and therefore are likely to display judicial behavior that is inconsistent, ramshackle, and ad hoc. The better judge, then, is the better philosopher; indeed, in Dworkin's view, a judge is always a philosopher whether he is aware of it or not, for "[a]ny practical legal argument, no matter how detailed and limited, assumes the kind of abstract foundation jurisprudence offers." Therefore, "any judge's opinion is itself a piece of legal philosophy, even when the philosophy is hidden." 35 Bad judges are judges whose philosophy is hidden from themselves; they follow instructions they have never properly considered and derive their arguments from distinctions they

29. R. Dworkin, Hard Cases, in Taking Rights Seriously 81, 112 (1977) [hereinafter R. Dworkin, Hard Cases].

30. Id. at 88.

31. Id. at 87 .

32. Id.

33. Id.

34. R. Dworkin, supra note 17 , at 90 .

35. Id. 
have never subjected to scrutiny. The good judge is supremely aware of his philosophy and is always in the process of both consulting and refining it whenever he takes up the task of making a decision about a fresh case. The choice is clear: One can either be an unreflective judge and be at the mercy of one's theory, or one can be in command of one's theory and use it as a mode of "calculation," to produce coherent and consistent opinions. $^{37}$

There is, however, in Dworkin's work a quite different picture of a judge's situation and activity, and while this different picture often sits side by side with the appeal to theory and the injunction to use theory, it finally reveals that appeal and injunction to be superfluous. I shall call that different picture an "enriched notion of practice,"38 a notion in which practice, rather than being in need of the guidance theory might claim to provide, is itself sufficient, is, in fact, self-sufficient, and in need of nothing additional. This notion often surfaces in Dworkin's writings and is in fact already present in the early essay The Model of Rules $I,^{39}$ where Dworkin says that legal principles, of the kind he urges us to apply, have their origin "not in a particular decision of some legislature or court, but in a sense of appropriateness developed in the profession ... over time." 40 In Dworkin's later work, this "sense of appropriateness" is developed into a description of law as a "chain enterprise," an enterprise in which agents see themselves as continuing the work of their predecessors." "Each judge must regard himself, in deciding the new case before him, as a partner in a complex chain enterprise of which . . . innumerable decisions, structures, conventions, and practices are the history; it is his job to continue that history into the future through what he does on the day." 12

What this suggests is that the agent embedded in a chain enterprise is

36. R. Dworkin, Hard Cases, supra note 29, at 109.

37. Dworkin's argument here derives from a venerable tradition (at least as venerable as the Socratic maxim that the unexamined life is not worth living) in which the highest of mental activities involves a self-conscious reflection on one's beliefs and assumptions. It is my thesis that since reflection so defined requires a space free of one's beliefs and assumptions it is not a possible achievement, and that to the extent that philosophy thinks of that achievement as its goal it will necessarily fail. See Fish, Critical Self-Consciousness or Can We Know What We're Doing?, in Critical InquiRY (forthcoming 1987).

38. See Fish, Anti-Professionalism, 7 Cardozo L. Rev. 645, 674-77 (1986) [hereinafter Fish, Anti-Professionalism]; Fish v. Fiss, supra note 3, at 1325-32; Fish, Wrong Again, 62 TEx. L. Rev. 299, 310-13 (1983) [hereinafter Fish, Wrong Again].

39. R. Dworkin, The Model of Rules I, in TAKINg Rights SERIously, supra note 29, at 14. 40. Id. at 40 .

41. See R. Dworkin, How Law Is Like Literature, in A Matter of Principle 146, 159 (1985); Dworkin, My Reply to Stanley Fish (and Walter Benn Michaels): Please Don't Talk About Objectivity Any More, in The Politics of InTerpretation (W.J.T. Mitchell ed. 1983). For my responses, see Fish, Working on the Chain Gang, 60 TEx. L. REv. 551 (1982); Fish, Wrong Again, supra note 38 .

42. R. Dworkin, supra note 41, at 159. 
the natural heir of the constraints that make up the chain's history. As a link in the chain he is a repository of the purposes, values, understood goals, forms of reasoning, modes of justification, etc. that the chain at once displays and enacts. It would follow then that an agent so embedded would not need anything external to what he already carried within him as a stimulus or guide to right-that is, responsible-action; in short, he would not need a theory. Dworkin, however, manages to arrive at just the opposite conclusion. He contrives to turn the insight that practice constrains into an argument for the necessity of constraints in excess of practice. And he does this because he sees the weight of practice-that is, of its history-not as something the agent thinks within, but as something the agent thinks with.

To think within a practice is to have one's very perception and sense of possible and appropriate action issue "naturally"-without further reflection-from one's position as a deeply situated agent. Someone who looks with practice-informed eyes sees a field already organized in terms of perspicuous obligations, self-evidently authorized procedures, and obviously relevant pieces of evidence. To think with a practice-by self-consciously wielding some extrapolated model of its working-is to be ever calculating just what one's obligations are, what procedures are "really" legitimate, what evidence is in fact evidence, and so on. ${ }^{43}$ It is to be a theoretician. Often Dworkin will begin by talking as if he imagines the agent in the first position-embedded within a practice in the sense that his every action is an extension of it; but he soon slides into imagining the agent-at least when he is expert-as happily distanced from practice's flow and in possession of some abstract formulation that insulates him against its pressures. Sometimes the shift occurs in the same sentence, as when he asserts in the essay Hard Cases, that "institutional history acts not as a constraint on the political judgment of judges but as an ingredient of that

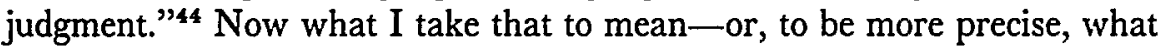
I want that to mean-is that at the moment when a judge sees a case in a certain way - as falling into this category, or requiring that kind of investigation-there would be no point to his consulting institutional history, because it is that history-not consulted but thoroughly internalized-that already constrains what he sees. As it turns out, however, that is not what Dworkin means at all, for he goes on to explain that institutional history is such an ingredient because it is "part of the background that any plau-

43. As Thompson Clark shows, theories which seek to answer "philosophical" questions about what is "really" legitimate (or true, or known) undercut themselves. They demand answers that are entirely detached from practical constraints; and yet it is only from within a constrained practice that asking the questions makes any sense. Clark, supra note 28 , at 765 .

44. R. Dworkin, Hard Cases, supra note 29, at 87. 
sible judgment must accommodate."45 With the word "accommodate," what seemed to have been together and indeed to have been one and the same-the shape of one's institutional history and the shape of one's judgment-are once again apart, with the first-institutional history-acting as a benchmark or minimal constraint to which the second-the act of judgment-must self-consciously conform. Moreover, in this picture-the picture in which theory is necessary-the agent could choose not to accommodate the institutional history and so proceed to act in an irresponsible and wayward manner. Finally, it is basic to Dworkin's view of the matter that theory-in the form of a coherent set of principles-operate as a constraint not only on an insufficiently constrained practice, but on an insufficiently constrained practitioner. Dworkin's inability to grasp the implications of an enriched notion of practice-even when he gestures in the direction of that notion-is at one with his inability to understand what it would mean to be an agent embedded in that practice, an agent who need not look to something in order to determine where he is or where he now might go because that determination is built into, comes along with, his already-in-place sense of being a competent member of the enterprise.

The distinction between my position and Dworkin's may seem small. After all, he, too, insists that the historical experience of practice is crucial. But the distinction is not small, but subtle and all important, and I feel it most strongly in those moments when I find myself rewriting one of Dworkin's sentences. In his new book, for example, he makes the following, apparently congenial, assertion: "Any judge will develop, in the course of his training and experience, a fairly individualized working conception of law on which he will rely, perhaps unthinkingly." this, I emend it (almost involuntarily) to "Any judge will develop into a working conception of law." The point of the emendation is to indicate the extent to which an experienced-that is practiced-judge is working simply by being what practice has enabled him to be; and, on that understanding, the clause "on which he will rely" should be changed to "which he will be." Thus, "any judge, in the course of his training and experience, will develop into a working conception of law, which he will be." One might object that in this new version of the sentence, the clause "which he will be" is redundant: If a judge develops into a working conception of law then, of course, that's what he is and nothing more need be said about the matter. Exactly right. There is nothing additional to say about it. The clause is superfluous for the same reason that theory is su-

45. Id.

46. R. DwoRkin, supra note 17 , at 256 . 
perfluous: The internalized "know how" or knowledge of "the ropes" that practice brings is sufficient unto the day and no theoretical apparatus is needed to do what practice is already doing, that is providing the embedded agent with a sense of relevancies, obligation, directions for action, criteria, etc.

But there may be other things to do, and theory might be needed to do one or more of them. It is time to acknowledge or reacknowledge the force of one of Dworkin's observations, that when judges themselves try to explain how it is that they work they present themselves as striving for just that articulate consistency that he sees as guiding the process of decisionmaking. And what is perhaps even more telling, judges engage in the same mode of self-presentation-a mode in which a present decision is explained or justified by an assertion of its fit with the principles underlying past decisions-when they hand down their decisions in the form of an opinion. How are we (that is, how am I) to account for this? Are judges concealing an unattractive truth? Or do they not know what they are doing? Not at all; they know perfectly well what they are doing. They are engaging in the practice of self-presentation, that is, the practice of offering a persuasive account of why they have done what they have done-decide the case this way rather than that-which is not the same thing (why on earth should it be?) as offering an account of how they actually did it. Dworkin is onto something really important in his elaborate discussion of the search for "articulate consistency" and the requirements it imposes; but what he is unto is not a mechanism by which decisions are generated, but the complex of rhetorical gestures to which one has recourse when a decision, already made, must be put into presentable form. Dworkin, in short, is a rhetorician.

The point can be made by returning to a sentence we have already considered and focusing this time on a single word: "Institutional history is part of the background that any plausible judgment . . . must accommodate." You will recall that my objection was to the word "accommodate," with its suggestion that institutional history was something the agent consults in the process of making a decision, whereas in my view the shape decisionmaking must take is immediately obvious to the agent for whom institutional history is the very ground of consciousness. But my objection disappears if the weight of Dworkin's assertion falls on the word "plausible"- "that any plausible judgment . . . must accommodate"-for that would indicate an obligation of a different kind from the obligation to consult or follow a theory. It would indicate an obligation to present one's decision in a form most likely to secure its acceptance; what Dworkin would be suggesting is that nowadays the form most likely to secure acceptance involves the fashioning of a story in which the present decision is 
the inevitable production of a principled and consistent history. ${ }^{47}$ In short, "articulate consistency" is not the name of a theoretical perspective from which decisions issue, but of a pragmatic strategy by means of which decisions are successfully inserted into a field of practice that requires of its decisions that they be filled with certain forms of talk, in this case with theory talk. Indeed in this view, theory would be no more (or less) than a kind of talk; it would be precisely the kind of talk one was advised to engage in when presenting one's decisions to members of the present legal community. A judge would do theory talk in the same way and for the same reason that the industrial researchers in our earlier example did it, not in order to provide an accurate description of the process by which they came upon their invention, but in order better to dress the product of that process in a garb appropriate to a situation in which their goal-and therefore the ground rules-had changed. Their goal is now persuasion, and they cast around for appropriate means with which to effect it (this is, of course, the traditional Aristotelian definition of rhetoric) and find them, or at least a portion of them, in the rhetorical practice of talking theory. Just as it would be inappropriate (indeed disastrous) for the researchers to begin by saying that "we were all sitting around one day, etc.," so would it be similarly inappropriate for a judge to say that "when I first saw this case, I saw it as already categorized and exhibiting certain characteristics and therefore calling for a certain description, and then I gave my clerk the assignment of putting together a story in which what I immediately saw was the product of a conscious act of intellection and deduction; and here's the story he brought back." 48 You just don't say that. You say something else and what you say must employ the vocabulary and tone of theory.

Once Dworkin has been recharacterized as a rhetorician rather than a theorist, much of what he says becomes quite acute and to the point, although not to the point he thinks himself to be making. Thus when he advises against historical, psychological, and sociological self-presentations,

47. Here then is a "consequence" of theory, not however of theory as a blueprint or script for practice, but of theory as an institutional phenomenon that has become so widespread that everyone feels obligated to lard his discourse with theory talk, just as in other contexts practitioners might feel obligated to lard their discourses with sports talk, or computer talk, or bio-feedback talk, or war talk, etc. In short, the consequences of theory are real, but they are political.

48. Of course one could imagine circumstances in which deciding and telling the story of the decision are simultaneous, not temporally distinct activities. That is, the decisionmaking process may well be one in which a judge "makes up his mind" (a phrase that might be taken literally) by reminding himself of the available forms of argument, and at some point such a judge might well say to himself, "I can't go in this direction, because I don't see how I could back it up." Thus, selfpresentation (to oneself) might be as much a part of the decisionmaking process as of the presentation of the decision to others. If this were so, the claims of theory would not thereby be revived; rather the claims of rhetoric would be extended, since not only the strategies of self-presentation, but the self that does the presenting would be rhetorically produced. 
on the grounds that "justification must be plausible and not sham,"48 he is saying something that is itself historical, psychological, and sociological: that given the way things are now in the law business, you had better not offer a justification that takes its terms from these disciplines, but takes them instead from moral or political philosophy because right now that's the going talk, and to slight it would be to risk losing the sympathy of your audience. What is and is not "sham" is entirely a matter of what in the discipline is currently thought to be the proper repository of evidence and argument. Sham is what won't work, or as Dworkin himself observes in the very next sentence, sham is what will be "unappealing;" if it is unappealing, then "it cannot count as a justification at all." Quite right. And Dworkin is right, too, when he labels the suggestion that we stop talking about "the law" and other big concepts in legal theory as "mostly bluff" because these concepts are "too deeply cemented into the structure of our political practices" to be so easily "given up." that what they are deeply cemented into is precisely a political practice, the practice of persuasively urging one's decision in the appropriate forum. In that forum, to stop talking in philosophically conceptual terms would be to make a big political (i.e., rhetorical) mistake. It would not be a mistake because it would falsify our picture of what judicial decisionmaking is like-it has no relation to that picture-but because philosophically conceptual terms are what the legal community now expects to hear when it listens to a self-presentation.

Of course, Dworkin would not accept my praise of him as a rhetorician, as someone who is telling us what kinds of stances and poses will best effect our polemical ends. He is not content with giving good rhetorical advice; he wants that advice to link up with a deep epistemological truth of which it is the reflection. He wants the observation that (at least in the current scene) you are more likely to be persuasive if you present yourself as having first built and then followed a theory to be heard as a description of and as a recipe for responsible decisionmaking. He wants to think of himself as telling us not simply how to dress, but how to be. The trouble is that by asking to be judged on the basis of that high aspiration-the aspiration to be a philosopher-king-Dworkin risks emptying his enterprise of any value or significance because as an epistemological recommendation it has nothing to offer us. What it purports to offer is a program for determining where a case fits, how it should be characterized, what its features are, and on what side of it one will find the right. But these are all judgments which come along with what Dworkin himself

49. R. Dworkin, Hard Cases, supra note 29, at 119.

50. Id.

51. R. Dworkin, Hard Cases, supra note 29, at 16. 
identifies as the "sense of appropriateness" with which and within which the fully initiated (i.e., practiced) member already sees. Such a member has no need of the help of an elaborated theory that has been designed to generate the sense of appropriateness he not only already has, but already is. ${ }^{.2}$

That is why Dworkin's repeated injunction to arrive at the "best" judgments we possibly can and be the best judges we can possibly be sounds so strange. One wants to say, with Dennis Martinez, "what else could we be or do except what, according to our lights, was the best?" That is, someone whose sense of appropriateness includes a firm conviction of what is and is not obligatory and what is and is not responsible judicial behavior will not have to look elsewhere for his convictions or for an understanding of what would be the "best" thing to do. "Be the best you can be" finally means nothing more than "act in the way your understanding of your role in the institution tells you to act." Like "throw strikes" and "keep "em off the bases," it is not an invitation to acquire new knowledge, but a reminder of what you already know. "Keep "em off the bases" could only have a positive content if a pitcher who thought himself to be acting as a pitcher could possibly decide to put as many men on base as he could; similarly, "Make your decisions the best they can be" could only have a positive content if a judge who thought himself to be acting as a judge could possibly decide to reach decisions that he would himself reverse on appeal. The pitcher who deliberately put men on base and the judge who issued willfully bizarre opinions would not be described as not having done their best, but as not having played their respective games. Those who are playing the game learn nothing from someone who tells them to be the best they can be. They are the recipients of the verbal equivalent of a pat on the back, and if Dworkin's claim is to be giving direction to judicial decisionmaking, the claim fails, and the best that he can be is a cheerleader. (G'mon fellows, do your best.)

All of this changes, however, if the injunction to search for the best justification of your decision is understood not as a method for producing that decision, but as a strategy for presenting it after it has already been made. Then the injunction has a positive content, and it tells you something. It tells you that only half your work is done and that, as things now stand, the way to do the second half-the way to be persuasive-is to construct a certain kind of story in which your decision is more or less dictated by the inexorable laws of the judicial process. Now Dworkin has a real project: to give you examples of how that story has been constructed

52. See Fish, supra note 3 , at $1345-47$ (one need not defend against nihilistic arguments by asserting existence of external constraints "because the necessary constraints are always already in place"). 
in the past and to provide you with rules of thumb that might be of help when you are asked to construct such a story in the future. It is not the project he announces; it is not the building of a grand theory. It is just a rhetoric, a manual of practical know-how; but precisely because it is a rhetoric and not a theory it might even be something you could actually use.

IV.

Yes, but use to what purpose, one might ask, and the answer a Critical Legal Studies adherent might give is, use to the purpose of extending and perpetuating the sham the law already is. That is to say, by redescribing Dworkin as the writer of a handbook for judicial self-presentation, I could be said to have put my finger on what is wrong with current judicial practice: Most of it consists of a massive effort to hide from itself and from the general public the rhetorical basis of its operations. This is what Unger means when he complains about the practice of retrospectively finding ways to make distinctions credible, and it is precisely the charge Mark Kelman makes in his essay, Interpretive Construction in the Substantive Criminal Law. ${ }^{\mathbf{5}}$ Kelman's thesis is that those who employ legal argument make claims for its rationality that cannot finally be maintained; they cannot be maintained because the steps in legal argument follow from an unacknowledged first step in which all the important questions are decided without reflection and, as it were, behind the institution's back. What results is what he calls "rational rhetoricism," lowing an apparently rational discourse to unfold with no acknowledgment whatsoever of the "non-rational" determinations that reside at its heart. Kelman, in short, is pointing to the truth I have been urging in this essay - the truth that the practice of deciding is one thing and the presentation in persuasive form of that decision another-and declaring it a scandal. The agent only "seems" to "deduce a single result on principle;")s in fact, the result proceeds from the hidden bias of a point of view already assumed and is then dressed up as a "legal-sounding argument."

Correctly understood, this is a complaint that agents are embedded in practice and that as long as they remain so-and remain so unthinkingly-they will never be able to see or to get a purchase on that which really informs their supposedly rational deliberations. We must, he says, be in a position where our "interpretive constructs"-those angles or pr-

53. 33 Stan. L. Rev. 591 (1981).

54. Id. at 592 .

55. Id.

56. Id. 
isms that give us our world and its "facts" have been made to surface; at that point, presumably, we will be less blinded by these constructs and less vulnerable to their now insidious (because covert) appeal. It is Kelman's effort in this essay to move us in the direction of that happy state and he proceeds by exposing or debunking those "interpretive constructs" which, in his view, are doing us the most damage.

Chief among these is the unthinking assumption of a "narrow time frame" within which the moment of criminal action is seen as coterminous with the physical act of pulling the trigger or snatching the purse; if the time frame were broadened and one understood an action as including many of its antecedents, including those social and economic pressures felt by the actor, then the assignment of responsibility would be rendered more problematical and a space would open up in which the question of determinism could be seriously raised. Kelman's complaint is that we never self-consciously debate the appropriateness of alternative time frames and thus enter upon our deliberations with many of the conceptual possibilities already excluded: "As best I can tell, we do these interpretive constructions utterly un-self-consciously. I have never seen or heard anyone declare that they are framing time broadly or narrowly, unifying or disjoining an incident, broadly or narrowly categorizing a defendant's . . . intent . . . let alone explain why they are doing it."

Kelman is, of course, right. He has never seen anyone self-consciously select his interpretative constructs, and indeed I would go further and say that no matter how long he lives it is a sight he will never see, because there has never been nor ever will be anyone who could survey interpretive possibilities from a vantage point that was not itself already interpretive. The demand for self-consciousness is a demand for a state of consciousness in which nothing has yet been settled and choices can therefore be truly rational. But if all concepts or constructs remained to be chosen, there would be nothing-no criteria, no norms of measurement, no calibration of value-with which or within which the choosing could be done; indeed there would be no chooser, for if the question of direction were totally open the mind (such as it is) would be incapable of going in any direction at all if only because it would be unable to recognize one.

To put the matter baldly, already-in-place interpretive constructs are a condition of consciousness. It may be, as Kelman laments, that the thinking that goes on within them is biased (which means no more than that it has direction) but without them (a pun seriously intended) there would be

57. Id. at 592-93.

58. Id. at 672 . 
no thinking at all. It follows then that the one thing you can't do in relation to interpretive constructs is choose them, and it follows too that you can't be faulted either for not having chosen them or for having chosen the wrong ones; moreover, it follows that it makes no sense to condemn as "non-rational" the reasoning that proceeds within interpretive constructs because that's the only kind of rationality there is. ${ }^{68}$ Finally, by the same reasoning, if you can't choose your interpretive constructs, then neither can you know them (in the sense of holding them in your hand for inspection), and if you can't know them, you can hardly be expected to take them into account when you come to explain the process by which you reached your conclusions. Kelman's essay begins as a complaint against the disparity between the self-presentation of action in the legal community and the true facts of the decisionmaking process; but if the true facts-the always prior operation of interpretive constructs-are not available to reflection, then the complaint is against something that could not be avoided. Rather than being an argument against my thesis of the two practices-deciding and presenting deciding-Kelman's examples flesh the thesis out by showing how impossible it would be to achieve the distance from our interpretive constructions that would be necessary if we were to be fully cognizant of the springs of our practice and could draw on that cognizance in our discourse about our discourse.

Nor is it the case that the hold our interpretive constructs have on us will be loosened simply because we have been alerted to it by Kelman and his friends. To think otherwise is to fall into the characteristically left error of assuming that an insight into the source of our convictions (they come from culture, not from God) will render them less compelling. ${ }^{60}$ If you have been persuaded to that insight you will be able, like Kelman, to tell a general story about where our convictions come from; but that story will not reflect one way or the other on any single one of them, which will or will not be in force depending on the extent to which this or that interpretive construction is doing its work. Remember what the general story says: Whatever you take to be the case about a matter will be a function of interpretive constructs you have not chosen; but the fact that you have now heard the story and believe it doesn't put you in any better position

59. See Fish, Wrong Again, supra note 38, at 310-12.

60. Duncan Kennedy and Robert Gordon make this same error. See Fish, Anti-Professionalism, supra note 38, at 656-61. I call this error "anti-foundationalist theory hope," the hope that because we now know that our foundations are interpretive rather than natural (given by God or nature), we will regard them with suspicion and shake ourselves loose from their influence. But any such hope rests on the possibility of surveying our interpretive foundations from a vantage point that was not itself interpretive; and the impossibility of doing that is the first tenet of anti-foundationalist thought. It follows then that anti-foundationalist thought cannot have the consequences that many hope that it will have, which is to say no more than that anti-foundationalism cannot itself (without contradiction) be made into a foundation. See Fish, supra note 13, at $440-41$. 
either to choose your interpretive constructs or to neutralize the effects of those you still will not have chosen.

"It is illuminating and disquieting," Kelman asserts, "to see that we are nonrationally constructing the legal world over and over again . . .."'s1 In fact, it is neither. It is not illuminating because it does not throw any light on any act of construction that is currently in force, for although your theory will tell you that there is always one (or more) under your feet, it cannot tell you which one it is or how to identify it. It is not disquieting because in the absence of any alternative to interpretive construction, the fact that we are always doing it is neither here nor there. It just tells us that our determinations of right and wrong will always occur within a set of assumptions that could not be subject to our scrutiny; but since everyone else is in the same boat, the point is without consequence and leaves us exactly where we always were, committed to whatever facts and certainties our interpretive constructions make available, and ready to do battle with those who, in the grip of other interpretive constructions, are certain of a different set of facts. Kelman's deconstructive theory finally has the same status as Moore's theory of epistemological realism and Dworkin's theory of articulate consistency: It is entirely irrelevant to the practice it purports to critique and reform. It can neither guide that practice nor disturb it. Indeed, the insight that interpretive constructs underlie our perceptions and deductions cannot do anything at all. It cannot act as a direction to seek something other than interpretive constructs, because there is no such other thing to be found; and it cannot act as a caution against the influence of interpretive constructions now in place because that influence will already be at work contaminating any effort to guard against it. In the end, Kelman's indignation that we do interpretive construction unself-consciously draws the now familiar Dennis Martinez response: What else could we do? It is a realization that goes nowhere, an epistemological or theoretical insight which is of no use at all.

It cannot even be useful as an ingredient in the practice of selfpresentation. ${ }^{62}$ Unlike Dworkin's notion of articulate consistency, the doctrine of rational rhetoricism cannot be recommended as a strategy to those who wish to make their arguments and opinions as persuasive as possible.

61. Kelman, supra note 53 , at 672 .

62. This is not entirely true. Readers of Kelman's article might well learn something useful from it. They might learn, for example, how to recharacterize a situation in a way that lessens the responsibility of a client or how to redefine an action so that a client's part in it is detached from any criminal consequences. If it were read in that spirit rather than as a serious call for the reform of our epistemological practice, the article would take on the dimensions of a rhetorical handbook not unlike those produced by Cicero and other early legal rhetoricians. The classical manuals typically open with two pieces of practice advice. Argue that your client didn't do it; and if that doesn't work, argue that it wasn't a crime. This is the lesson that Kelman teaches even as he laments its effectiveness. 
Imagine the judge or lawyer who makes every point in the company of the demonstration that the point depends on assumptions that one could always challenge. Imagine, too, that same judge or lawyer on the alert for those moments when his own discourse is in danger of becoming convincing, and meeting that danger by analyzing and laying bare the wholly rhetorical conditions that give force to what he has been saying. It would be too little to say of such a performer that he was falling down on the job of lawyering or judging; he wouldn't be doing that job at all, but some other, the job of literary criticism or of continental philosophizing. What Kelman and those who agree with him fail to understand is that no activity or practice can take into consideration everything that could possibly be taken into consideration, because it is the very definition of an activity or practice that it is an attempt to do this rather than that.

In a recently published book, Peter Goodrich has complained that in "constructing the abstract world" of law-the world in which actions are easily specifiable and responsibility can always be determined-members of the legal community "have tended to be forgetful both of the irrationality and chance embedded in social life as well as of the instability and change intrinsic to human purpose and human personality." would it mean for actors in the legal community to be not forgetful of these things, indeed to have them uppermost in their minds, dictating the shape of their thoughts? It would mean that they would not be legal actors, but psychologists, or sociologists, or statisticians. "Forgetfulness," in the sense of not keeping everything in mind at once, is a condition of action, and the difference between activities-between doing judging and doing literary criticism or doing sociology-is a difference between differing species of forgetfulness. The absurdity of demanding that everything be remembered is illustrated by Kelman's accusation that in framing and administering criminal law "we simply rule out the determinist claim that "crime is unavoidable." "'B4 But all this means is that in order for there to be a criminal law, the claim of determinism cannot seriously be entertained, except as a fringe or special case-insanity, mental incapacity-which bounds and protects a central area of personal responsibility. It can hardly be a complaint against the criminal law that it pays little and selective attention to a point of view that would undo it. What Kelman is really complaining about is that there is a criminal law at all.

Now that, of course, is a perfectly reasonable complaint. If the criminal law depends on notions of personal responsibility and autonomous action which seem retrograde and harmful, perhaps we should do something to

63. P. GOOdRICH, Reading the LAW 209 (1986).

64. Kelman, supra note 53 , at 611 . 
get rid of it. Perhaps so, but we won't get rid of it by assaulting it with a philosophical argument, even one that shows it to be less firmly grounded than many had assumed. That might be a knock-down argument in philosophy, but, despite what Dworkin and others might believe, law is not philosophy, and it will not fade away because a few guys in Cambridge and Palo Alto are now able to deconstruct it.

I can imagine Kelman and Dworkin and Moore and a host of others objecting that I still have not dealt with the most obvious deficiency of a legal culture that is not somehow undergirded by reason, by a theory: It leaves us with a field of practice that is ramshackle and inconsistent. As Kelman puts it, "the solution to legal dilemmas is inevitably partial. The 'victory' of one framework or the other is a temporary one that can never be made with assurance." $6 \mathrm{Or}$ in the words of Roberto Unger, law, in the absence of some cohesive and coherent view, is simply "an endless series of ad hoc adjustments," "a collection of makeshift apologies." tion I would ask is "makeshift in relation to what?" Surely not in relation to the pressures and urgencies that make a solution satisfying or an adjustment helpful. The answer, as we have already seen, is makeshift in relation to a description of our several and various actions which would show them to follow from a single set of abstract principles, from a theory. But what that means is that "makeshift" and "ad hoc" are accusations not of our practices as they pursue their several goals, but of our practices as if it were their single goal to be available to a philosophical description. But if our practices had that goal, they wouldn't be our practices. They would be philosophy; ${ }^{67}$ indeed, that is finally what the demand for theory and consistency amount to, a demand that there be only one practice and that philosophy be its name. Now there is, of course, a practice named philosophy, and it is in the business of abstracting away from other practices in order to see what can be said about things in general. But it seems bizarre to think that this should also be the business of practices that are not philosophy, to think that it is the obligation of agents in other practices periodically to rouse themselves and say "hey, what we're really doing is philosophy even though we call it judging or literary criticism, so let's consult some philosophers so that we can see if we're doing it right or doing it in some ad hoc or ramshackle way." It is hard to imagine why agents genuinely committed to a practice would hand over responsibility for judging it to some other practice, especially to a practice that takes place almost exclusively in college classrooms. It is quite easy to imagine why philosophers would think that an abdication in their direc-

65. Id. at 597.

66. Unger, supra note 18 , at 572-73.

67. See Clark, supra note 28 , at 760 . 
tion makes perfect sense. Philosophers, after all, are like anyone else; they want people who don't do what they do to believe that what they do is universally enabling. They want us to believe that the only good king is a philosopher-king, and that the only good judge is a philosopher judge, and that the only good baseball player is a philosopher baseball player. Well, I don't know about you, but I hope that my kings, if I should ever have any, are good at being kings, and that my judges are good at being judges, and that the players on my team throw strikes and keep 'em off the bases. 